\title{
Sustained Diurnal Stimulation of Cyclic Electron Flow in Two Tropical Tree Species Erythrophleum guineense and Khaya ivorensis
}

\author{
Wei Huang ${ }^{1,2 *}$, Ying-Jie Yang ${ }^{1,2+}$, Hong Hu ${ }^{1,2}$, Kun-Fang Cao ${ }^{3}$ and Shi-Bao Zhang ${ }^{1,2 *}$ \\ ${ }^{1}$ Key Laboratory of Economic Plants and Biotechnology, Kunming Institute of Botany - Chinese Academy of Sciences, \\ Kunming, China, ${ }^{2}$ Yunnan Key Laboratory for Wild Plant Resources, Kunming, China, ${ }^{3}$ Key Laboratory of Tropical Forest \\ Ecology, Xishuangbanna Tropical Botanical Garden - Chinese Academy of Sciences, Mengla, China
}

OPEN ACCESS

Edited by:

Suleyman I. Allakhverdiev, Russian Academy of Sciences, Russia

Reviewed by:

Xinguang Zhu,

University of Chinese Academy

of Sciences, China

Marek Zivcak,

Slovak University of Agriculture,

Slovakia

Marian Brestic

Slovak University of Agriculture, Slovakia

*Correspondence: Wei Huang

huangwei@mail.kib.ac.cn

Shi-Bao Zhang

sbzhang@mail.kib.ac.cn

${ }^{t}$ These authors have contributed equally to this work.

Specialty section: This article was submitted to Plant Physiology, a section of the journal Frontiers in Plant Science

Received: 22 February 2016 Accepted: 06 July 2016 Published: 19 July 2016

Citation:

Huang $W$, Yang $Y-J$, Hu $H$, Cao $K-F$ and Zhang S-B (2016) Sustained

Diurnal Stimulation of Cyclic Electron Flow in Two Tropical Tree Species

Erythrophleum guineense and Khaya ivorensis. Front. Plant Sci. 7:1068.

doi: 10.3389/fpls.2016.01068
The photosystem II (PSII) activity of $\mathrm{C}_{3}$ plants is usually inhibited at noon associated with high light but can be repaired fast in the afternoon. However, the diurnal variation of photosystem I (PSI) activity is unknown. Although, cyclic electron flow (CEF) has been documented as an important mechanism for photosynthesis, the diurnal variation of CEF in sun leaves is little known. We determined the diurnal changes in PSI and PSII activities, light energy dissipation in PSII and the P700 redox state in two tropical tree species Erythrophleum guineense and Khaya ivorensis grown in an open field. The PSI activity (as indicated by the maximum quantity of photo-oxidizable P700) was maintained stable during the daytime. CEF was strongly activated under high light at noon, accompanying with high levels of non-photochemical quenching (NPQ) and PSI oxidation ratio. In the afternoon, CEF was maintained at a relatively high level under low light, which was accompanied with low levels of NPQ and P700 oxidation ratio. These results indicated that CEF was flexibly modulated during daytime under fluctuating light conditions. Under high light at noon, CEF-dependent generation of proton gradient across the thylakoid membranes $(\Delta \mathrm{pH})$ mainly contributed to photoprotection for PSI and PSII. By comparison, at low light in the afternoon, the CEF-dependent formation of $\Delta \mathrm{pH}$ may be important for PSIl repair via an additional ATP synthesis.

Keywords: cyclic electron flow, photoprotection, photosystem I, photosystem II, recovery

\section{INTRODUCTION}

Light is the driving force for photosynthesis. However, excess light excitation could lead to photoinhibition (Powles, 1984; Barber and Andersson, 1992; Aro et al., 1993). High light stress usually causes selective photoinhibition of photosystem II (PSII; Barber and Andersson, 1992; Prasil et al., 1992; Asada, 1996, 1999). Photoinhibition of PSII occurs only when the rate of photodamage to PSII exceeds the rate of its repair (Aro et al., 1993; Murata et al., 2007; Takahashi and Murata, 2008; Takahashi et al., 2009). Under conditions in which absorbed light is in excess of the requirement of photosynthesis, excess light energy leads to the production of reactive oxygen species (ROS; Murata et al., 2007). It has been indicated that the ROS accelerate PSII photoinhibition mainly through inhibition of the repair of photodamaged PSII (Nishiyama et al., 2001, 2004), although some exceptions indicate that ROS cause direct photodamage 
to PSII (Oguchi et al., 2009). To avoid severe irreversible photodamage to PSII, plants have several photoprotective mechanisms to diminish the rate of photodamage and favor the repair of photodamaged PSII, including adjusting PSII connectivity (Zivcak et al., 2014), thermal energy dissipation (Niyogi et al., 1998, 2001), and cyclic electron flow (CEF) around PSI (Munekage et al., 2002, 2004; Takahashi et al., 2009; Huang et al., 2011; Suorsa et al., 2012; Brestic et al., 2015; Zivcak et al., 2015).

Plants have the ability to dissipate excess light energy harmlessly as heat through non-photochemical quenching (NPQ; Niyogi et al., 1998, 2001), which is dependent on not only xanthophyll cycle, i.e., the de-epoxidation of violaxanthin to zeaxanthin via antheraxanthin (Demmig-Adams, 1990), but also the establishment of a proton gradient across the thylakoid membranes ( $\Delta \mathrm{pH}$; Munekage et al., 2002, 2004; Nandha et al., 2007). Leaves grown under high light usually have stronger capacity to fulfill the NPQ process by the enhancements of xanthophyll cycle and CEF activities (Miyake et al., 2005; Ballottari et al., 2007). CEF-dependent generation of $\Delta \mathrm{pH}$ helps to alleviate photoinhibition by at least two different photoprotection mechanisms: one is linked to thermal energy dissipation ( $\mathrm{qE}$ ) generation and prevents the inhibition of the repair of photodamaged PSII, and the other is independent of $\mathrm{qE}$ and suppresses the photodamage to PSII (Takahashi et al., 2009). As a result, impairment of CEF could lead to severe photoinhibition of PSII under high light (Takahashi et al., 2009). The increases in leaf-to-air vapor pressure deficit and air temperature at noon induce a decrease in photosynthetic rate (Zhang et al., 2009), which subsequently results in PSII photoinhibition (Takahashi and Murata, 2005, 2006; Murata et al., 2007). Meanwhile, plants display high levels of NPQ at noon. Therefore, we speculate that CEF is strongly stimulated in sun leaves at noon associated with high light to promote NPQ.

Photoinhibited PSII at noon could be repaired fast in the afternoon (Allen et al., 2000; He and Chow, 2003; Hendrickson et al., 2004a). It has been reported that photoinhibition of PSII can be quickly repaired at low light unless PSI activity is extremely inhibited (Sundby et al., 1993; He and Chow, 2003; Zhang and Scheller, 2004; Huang et al., 2010a). The fast repair of PSII photoinhibition is dependent on rapid synthesis of bioenergy (ATP) which requires the generation of $\Delta \mathrm{pH}$ across thylakoid membranes (Allakhverdiev et al., 2005). It has been indicated that CEF can help ATP synthesis under low light in Arabidopsis thaliana (Nishikawa et al., 2012), rice (Yamori et al., 2011), and tobacco (Wang et al., 2006; Huang et al., 2015). A previous study indicated that CEF was stimulated under low light during the recovery after chilling-induced photoinhibition of PSII (Huang et al., 2010b). Since ATP synthesis might regulate the repair of PSII (Allakhverdiev et al., 2005), we speculate that CEF is stimulated in the afternoon to generate the ATP and then help the fast repair of PSII photoinhibition.

Photoinhibition of PSI is mainly caused by the oxidation of hydroxyl radical that is usually generated by a reaction between hydrogen peroxide and a reduced metal ion in a process called the Fenton reaction (Asada and Takahashi, 1987; Sonoike, 1996a,b). Thus, there are two necessary mechanisms responsible for PSI photoinhibition: over generation of hydrogen peroxide and over reduction of PSI reaction centers (Sonoike, 1995; Munekage et al., 2002, 2004; Tikkanen et al., 2014). Active electron flow from PSII is necessary for photoinhibition of PSI in chilled cucumber (Havaux and Davaud, 1994; Sonoike, 1995). In the PROTON GRADIENT REGULATOR5 (pgr5) plants of A. thaliana, PSI is extreme sensitive to high light stress (Munekage et al., 2002; Suorsa et al., 2012; Kono et al., 2014; Tikkanen et al., 2014). Photoinhibition of PSI severely affects $\mathrm{CO}_{2}$ assimilation and photoprotection in wheat leaves (Brestic et al., 2015; Zivcak et al., 2015). CEF around PSI has been documented as an important mechanism for protecting PSI from photoinhibition under high light because the activation of CEF contributes to the oxidation of P700 and alleviates over-reduction of the PSI acceptor side (Munekage et al., 2002, 2004; Kono et al., 2014; Tikkanen et al., 2014, 2015). P700 ${ }^{+}$can dissipate excess excitation energy harmlessly and thus alleviate photoinhibition of PSI. Moreover, stimulation of CEF could alleviate the over accumulation of the reducing power NADPH and then diminished the generation of ROS in PSI acceptor side, especially at high temperature (Wang et al., 2006; Essemine et al., 2016). High levels of light condition and leaf temperature are typical conditions in clear days in summer. We speculate that stimulation of CEF under high light at noon favors the photoprotection for PSI.

In our present study, we determined the diurnal changes in PSI and PSII activities, light energy quenching in PSII and P700 redox state for leaves of two tropical tree species Erythrophleum guineense and Khaya ivorensis grown in an open field. The following questions were addressed: (1) Is PSI activity maintained stable during the daytime? (2) Is CEF stimulated at low light in the afternoon for the fast repair of PSII photoinhibition? (3) Is the role of CEF regulated flexibly during the daytime with fluctuation of light condition?

\section{MATERIALS AND METHODS}

\section{Plant Materials}

Two tropical tree species were chosen for the present study. E. guineense G. Don (Fabaceae) is a large canopy species native to tropical Africa. K. ivorensis A. Chev (Meliaceae) is a large canopy species found in various habitat types in west and central tropical Africa but is most abundant in wet undisturbed evergreen forests. Potted 2-years-old seedlings of E. guineense and K. ivorensis were used for experiments. Plants of these two species grown well in an open field in Xishuangbanna Tropical Botanical Garden $\left(21^{\circ} 54^{\prime} \mathrm{N}, 101^{\circ} 46^{\prime} \mathrm{E}\right)$. We conducted all measurements in 4 days in summer (16 August, 19 August, 21 August, and 23 August in 2013). The diurnal changes in photosynthetic photon flux density (PPFD) are indicated in Figure 1. During these periods, the air temperature changed from $20^{\circ} \mathrm{C}$ at night to $32^{\circ} \mathrm{C}$ in the daytime.

\section{Chlorophyll Fluorescence and P700 Redox State Measurements}

We synchronously measured the light responses of chlorophyll fluorescence and P700 redox state at $25^{\circ} \mathrm{C}$ with Dual PAM100 (Heinz Walz, Effeltrich, Germany) connected to a computer 


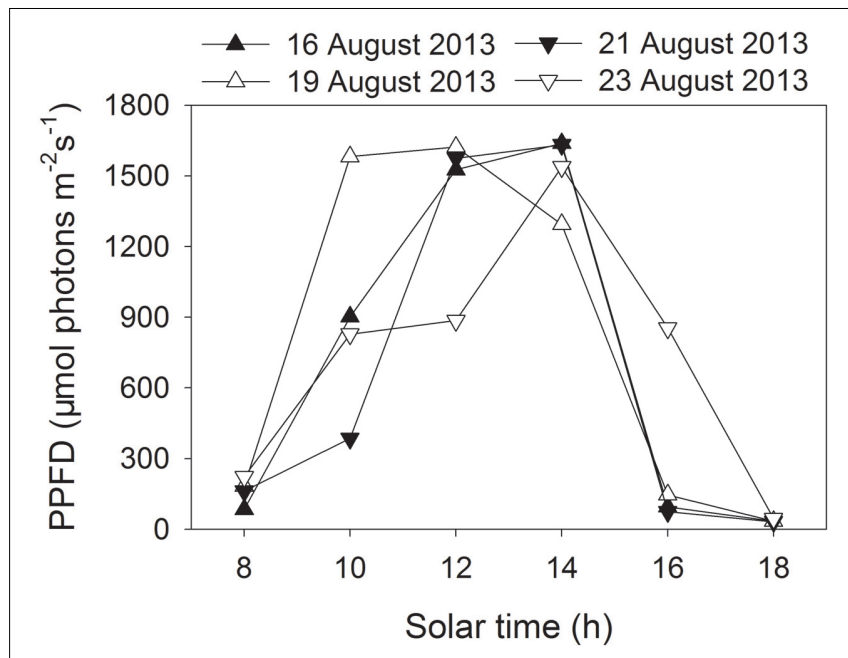

FIGURE 1 | Diurnal change in photosynthetic photon flux density (PPFD) on 4 days in summer (16 August, 19 August, 21 August, 23 August 2013) in an open site.

with control software. In the present study, a $635 \mathrm{~nm}$ LED was used as actinic light. We conducted the measurements of light response curves in the morning. In order to eliminate the effect of photoinhibition on measurements of light response curves, the potted plants were transferred to a shade place the night before. Mature leaves were light-adapted $\left(360 \mu \mathrm{mol}\right.$ photons $\left.\mathrm{m}^{-2} \mathrm{~s}^{-1}\right)$ for at least $20 \mathrm{~min}$ at $25^{\circ} \mathrm{C}$ before the measurement of light response curves, and light-adapted photosynthetic parameters were recorded after $3 \mathrm{~min}$ exposure to each light intensity (1957, $1599,1292,830,536,221,131,58$, and $18 \mu \mathrm{mol}$ photons $\mathrm{m}^{-2}$ $\left.\mathrm{s}^{-1}\right)$.

The diurnal PSI and PSII parameters were conducted on five to six intact leaves on clear days every $2 \mathrm{~h}$ in daytime. The ambient PPFD was measured with a micro-quantum sensor connected to a Licor 1400 data logger. In the present study, $3 \mathrm{~min}$ of $635 \mathrm{~nm}$ red actinic LED light corresponding to the natural PPFD at a given solar time was used for measurements of chlorophyll fluorescence and P700 redox state. The time lag between measured PPFD and the onset of the measurements of the fluorescence and P700 was $3 \mathrm{~min}$. During the time lag, the measured leaves were incubated in darkness, which favors the later measurement of the maximum quantum yield of P700 $\left(P_{m}\right)$. After measuring light-adapted chlorophyll fluorescence and P700 redox state, the leaves were incubated in darkness for $20 \mathrm{~min}$ and then the maximum quantum yield of PSII $\left(F_{v} / F_{m}\right)$ and $P_{m}$ were measured. There were no significant differences between the values of $P_{m}$ measured after 3 or 20 min incubation in darkness in the two species. As a result, we used the value of $P_{m}$ measured after 3 min incubation in darkness in our present study.

The fluorescence parameters were calculated as follows: $F_{v} / F_{m}=\left(F_{m}-F_{o}\right) / F_{m}, \quad F_{o}{ }^{\prime}=F_{o} /\left(F_{v} / F_{m}+F_{o} / F_{m}{ }^{\prime}\right)$ (Oxborough and Baker, 1997), $F_{v}{ }^{\prime} / F_{m}{ }^{\prime}=\left(F_{m}{ }^{\prime}-F_{o}{ }^{\prime}\right) / F_{m}{ }^{\prime}$, $\mathrm{qP}=\left(F_{m}{ }^{\prime}-F_{s}\right) /\left(F_{m}{ }^{\prime}-F_{o}{ }^{\prime}\right), \mathrm{Y}(\mathrm{II})=\left(F_{m}{ }^{\prime}-F_{s}\right) / F_{m}{ }^{\prime}$ (Genty et al., 1989), $\mathrm{Y}(\mathrm{NO})=F_{s} / F_{m}, \mathrm{Y}(\mathrm{NPQ})=F_{s} / F_{m}{ }^{\prime}-F_{s} / F_{m}$ (Hendrickson et al., 2004b; Kramer et al., 2004), where $F_{o}$ and
$F_{o}{ }^{\prime}$ are the minimum fluorescence values in the dark-adapted and light-adapted states, respectively. Notably, the value of $F_{o}{ }^{\prime}$ was calculated according to the above equation. $F_{m}$ and $F_{m}{ }^{\prime}$ are the maximum fluorescence values upon illumination of pulse $(300 \mathrm{~ms})$ of saturating light $\left(10000 \mu \mathrm{mol} \mathrm{m} \mathrm{m}^{-2} \mathrm{~s}^{-1}\right)$ in the dark-adapted and light-adapted state, respectively. $F_{s}$ is the steady state chlorophyll fluorescence value in a light-acclimated state. Y(II) is the effective quantum yield of PSII. Y(NO) is the quantum yield of non-regulated energy dissipation. Y(NPQ) is the fraction of energy dissipated in form of heat via the regulated NPQ mechanism.

The PSI parameters were measured with a dual wavelength $(830 / 875 \mathrm{~nm})$ unit, following the method of Klüghammer and Schreiber $(1994,2008)$. Saturation pulses (10000 $\mu \mathrm{mol}$ photons $\left.\mathrm{m}^{-2} \mathrm{~s}^{-1}\right)$, were applied for assessment of P700 parameters as well (Klüghammer and Schreiber, 2008). The P700 ${ }^{+}$signals $(P)$ may vary between a minimal (P700 fully reduced) and a maximal level (P700 fully oxidized). The maximum level, which in analogy to $F_{m}$ is called $P_{m}$, was determined with application of a saturation pulse during illumination with far-red light. At a defined optical property, the amplitude of $P_{m}$ depends on the maximum amount of photo-oxidizable P700, which is a good parameter for representing PSI activity (Huang et al., 2010a,b, 2013; Suorsa et al., 2012; Kono et al., 2014; Tikkanen et al., 2014). $P_{m}{ }^{\prime}$ was also defined in analogy to the fluorescence parameter $F_{m}{ }^{\prime} . P_{m}{ }^{\prime}$ was determined similarly to $P_{m}$, but with background actinic light instead of far-red illumination. The photochemical quantum yield of PSI, Y(I), is defined by the fraction of overall P700 that in a given state is reduced and not limited by the acceptor side. It is calculated as $\mathrm{Y}(\mathrm{I})=\left(P_{m}{ }^{\prime}-P\right) / P_{m} . \mathrm{Y}(\mathrm{ND})=P / P_{m}$, represents the fraction of $\mathrm{P} 700$ that is already oxidized in a given state. $\mathrm{Y}(\mathrm{NA})=\left(P_{m}-P_{m}{ }^{\prime}\right) / P_{m}$, thus represents the fraction of P700 that cannot be oxidized by a saturation pulse to the overall P700.

Photosynthetic electron flow through PSI and PSII was calculated as follows: ETRI $=$ PPFD $\times \mathrm{Y}(\mathrm{I}) \times 0.85 \times \alpha \mathrm{I}$, ETRII $=$ PPFD $\times \mathrm{Y}(\mathrm{II}) \times 0.85 \times \alpha$ II. 0.85 is assumed to be the leaf absorbance. $\alpha$ I and $\alpha$ II represent the fractions of the absorbed light distributed to PSI and PSII, respectively. In our present study, $\alpha$ I and $\alpha$ II are calculated using values of $Y(I)$ and $\mathrm{Y}(\mathrm{II})$ under $18 \mu \mathrm{mol}$ photons $\mathrm{m}^{-2} \mathrm{~s}^{-1}$ according to the method of Huang et al. (2012) and Zivcak et al. (2013).

\section{Statistical Analysis}

The results were displayed as mean values of four to six independent experiments. The data were subjected to analysis of variance (ANOVA) using the SPSS 16.0 statistical software. Tukey's multiple comparison test was used at $\alpha=0.05$ significance level to determine whether significant differences exist among different treatments.

\section{RESULTS}

\section{Light Response Changes in Energy Quenching in PSII and P700 Redox State}

With increasing light intensity, the decrease in $\mathrm{qP}$ was larger than that of $F_{v}{ }^{\prime} / F_{m}{ }^{\prime}$. As a result, the effective quantum yield of 

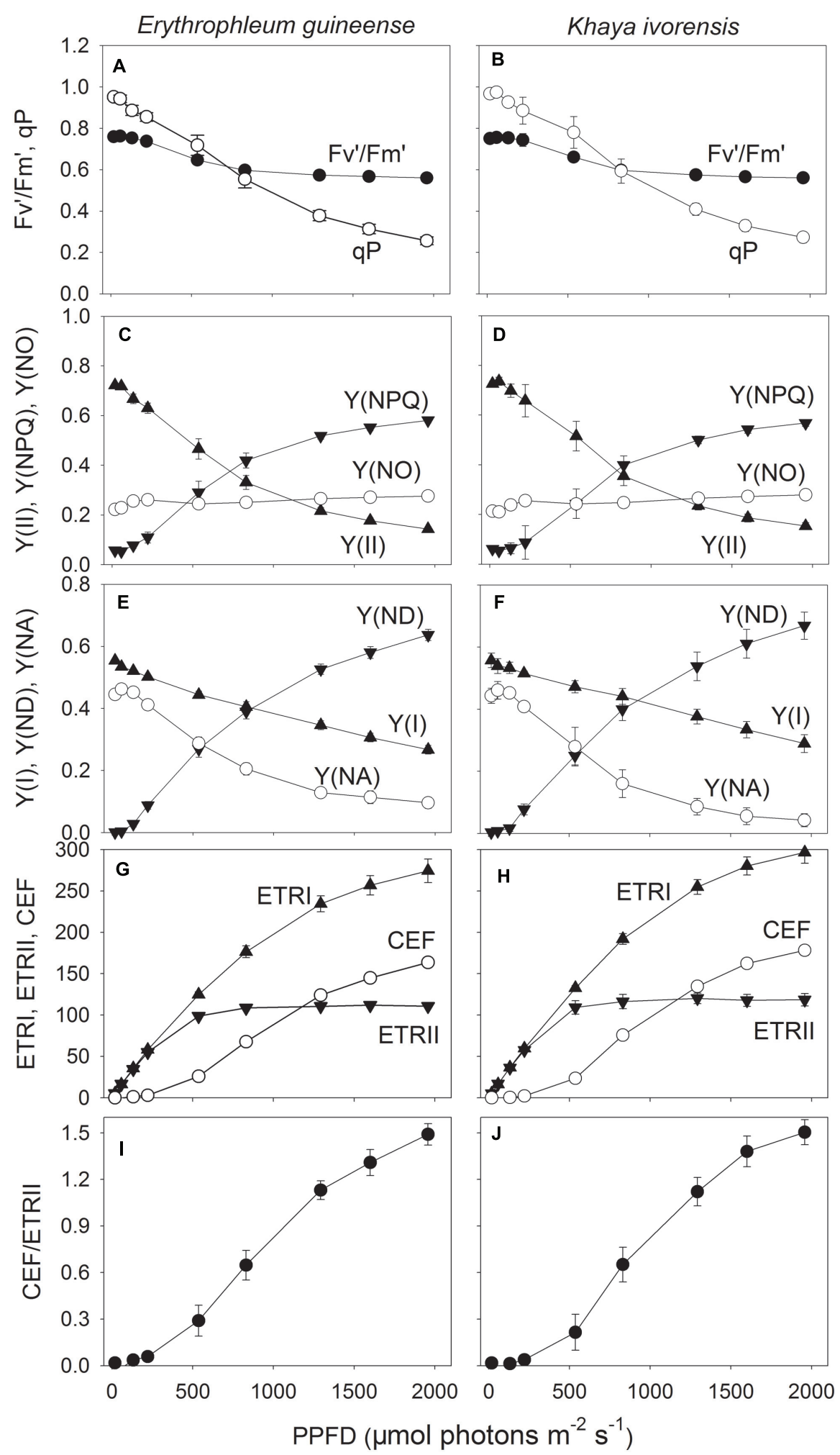

FIGURE 2 | Light response changes (A-J) in $F_{v^{\prime}} / F_{m^{\prime}}{ }^{\prime}, \mathrm{qP}, \mathrm{Y}(\mathrm{II}), \mathrm{Y}(\mathrm{NPQ}), \mathrm{Y}(\mathrm{NO}), \mathrm{Y}(\mathrm{I}), \mathrm{Y}(\mathrm{ND}), \mathrm{Y}(\mathrm{NA})$, ETRI, ETRII, CEF, and CEF/ETRII ratio for leaves of E. guineense and $K$. ivorensis measured at $25^{\circ} \mathbf{C}$ without photoinhibition. $F_{v}^{\prime} / F_{m}^{\prime}$, maximum quantum yield of $\mathrm{PSIl}$ under light; $\mathrm{qP}$, coefficient of photochemical quenching; $Y(I I)$, effective quantum yield of $P S I I ; Y(N P Q)$, fraction of energy dissipated in form of heat via the regulated non-photochemical quenching mechanism; $Y(N O)$, fraction of energy that is passively dissipated in form of heat and fluorescence; $Y(I)$, effective quantum yield of PSIl; $Y(N D)$, fraction of overall P700 that is oxidized in a given state; $Y(N A)$, fraction of overall P700 that cannot be oxidized in a given state; ETRI, photosynthetic electron flow through PSI; ETRII, photosynthetic electron flow through PSII; CEF, cyclic electron flow. The mean \pm SE was calculated from six plants. 
PSII [Y(II)] gradually decreased with increasing light intensity, mainly due to the decrease in $\mathrm{qP}$ (Figures 2A-D). Meanwhile, the fraction of energy dissipated as heat via the regulated [Y(NPQ)] strongly increased (Figures 2C,D). The quantum yield of nonregulated energy dissipation in PSII [Y(NO)] was maintained stable near the baseline of 0.2 in the two species (Figures 2C,D). The value of quantum yield of PSI [Y(I)] gradually decreased with increasing light intensity in the two species (Figures 2E,F). Meanwhile, the faction of P700 that is already oxidized in a given state $[\mathrm{Y}(\mathrm{ND})]$ largely increased with an increase in light intensity. The fraction of overall P700 that cannot be oxidized in a given state $[\mathrm{Y}(\mathrm{NA})]$ was maintained at a low level of approximately 0.1 under high light in the two species (Figures 2E,F).

At light intensities below $221 \mu \mathrm{mol}$ photons $\mathrm{m}^{-2} \mathrm{~s}^{-1}$, the value of ETRI approximately equaled ETRII, resulting in little activation of CEF (Figures 2G,H). Values for ETRII reached the maximum at a light of $830 \mu \mathrm{mol}$ photons $\mathrm{m}^{-2} \mathrm{~s}^{-1}$, but ETRI gradually increased with an increase in light intensity in both species (Figures 2G,H). Accordingly, CEF was activated at light intensities above $536 \mu \mathrm{mol}$ photons $\mathrm{m}^{-2} \mathrm{~s}^{-1}$ and increased gradient with increasing light intensity. The CEF/ETRII ratio showed similar trend as CEF (Figures 2I,J). Combining with the light response changes in $\mathrm{Y}(\mathrm{NPQ}), \mathrm{Y}(\mathrm{ND})$, and $\mathrm{Y}(\mathrm{NA})$, the large difference in CEF/ETRII ratio between low light and high light indicated the stimulation of CEF around PSI under high light in both species.

\section{Diurnal Change in Energy Distribution in PSII and P700 Redox State}

During clear summer days, the maximum quantum yield of PSII $\left(F_{v} / F_{m}\right)$ decreased significantly at noon and recovered fast in the afternoon in both species (Figures 3A,B), indicating the high-light-induced PSII photoinhibition. At noon, both $F_{v}{ }^{\prime} / F_{m}{ }^{\prime}$ and $\mathrm{qP}^{\mathrm{P}}$ significantly decreased, leading to a decrease in $\mathrm{Y}(\mathrm{II})$ (Figures 3C-H). In the afternoon, when the light intensity was low, Y(II) fast recovered due to an increase in both $F_{v}{ }^{\prime} / F_{m}{ }^{\prime}$ and qP (Figures $3 \mathbf{C}-\mathbf{H})$. The value of $\mathrm{Y}(\mathrm{NPQ})$ was maintained a low level in the early morning and the late afternoon, but largely increased at noon to dissipate excess absorbed light energy in the two species (Figures 3I,J). The value of $\mathrm{Y}(\mathrm{NO})$ increased at noon and decreased in the afternoon, indicating a detrimental effect of excess light energy, at noon, on PSII (Figures 3K,L).

The $P_{m}$ was maintained stable during the daytime (Figures 4A,B), indicating the maintenance of the stable amount of P700 active reactions centers and thus stable activity of PSI during the daytime. Since PSI photoinhibition can be affected by the redox state of P700, values for $\mathrm{Y}(\mathrm{I}), \mathrm{Y}(\mathrm{ND})$, and $\mathrm{Y}(\mathrm{NA})$ were measured to examine the diurnal change in P700 redox state. The value of $\mathrm{Y}(\mathrm{I})$ significantly decreased at noon and recovered fast in the afternoon (Figures 4C,D). Under high light at noon, $\mathrm{Y}(\mathrm{ND})$ was maintained at high levels at noon, and $\mathrm{Y}(\mathrm{NA})$ was maintained at low level of approximately 0.1 (Figures 4E-H), indicating the over-reduction of PSI acceptor side was prevented under high light. At low light intensities in the afternoon, both species showed low levels of $\mathrm{Y}(\mathrm{ND})$ (Figures 4E,F).

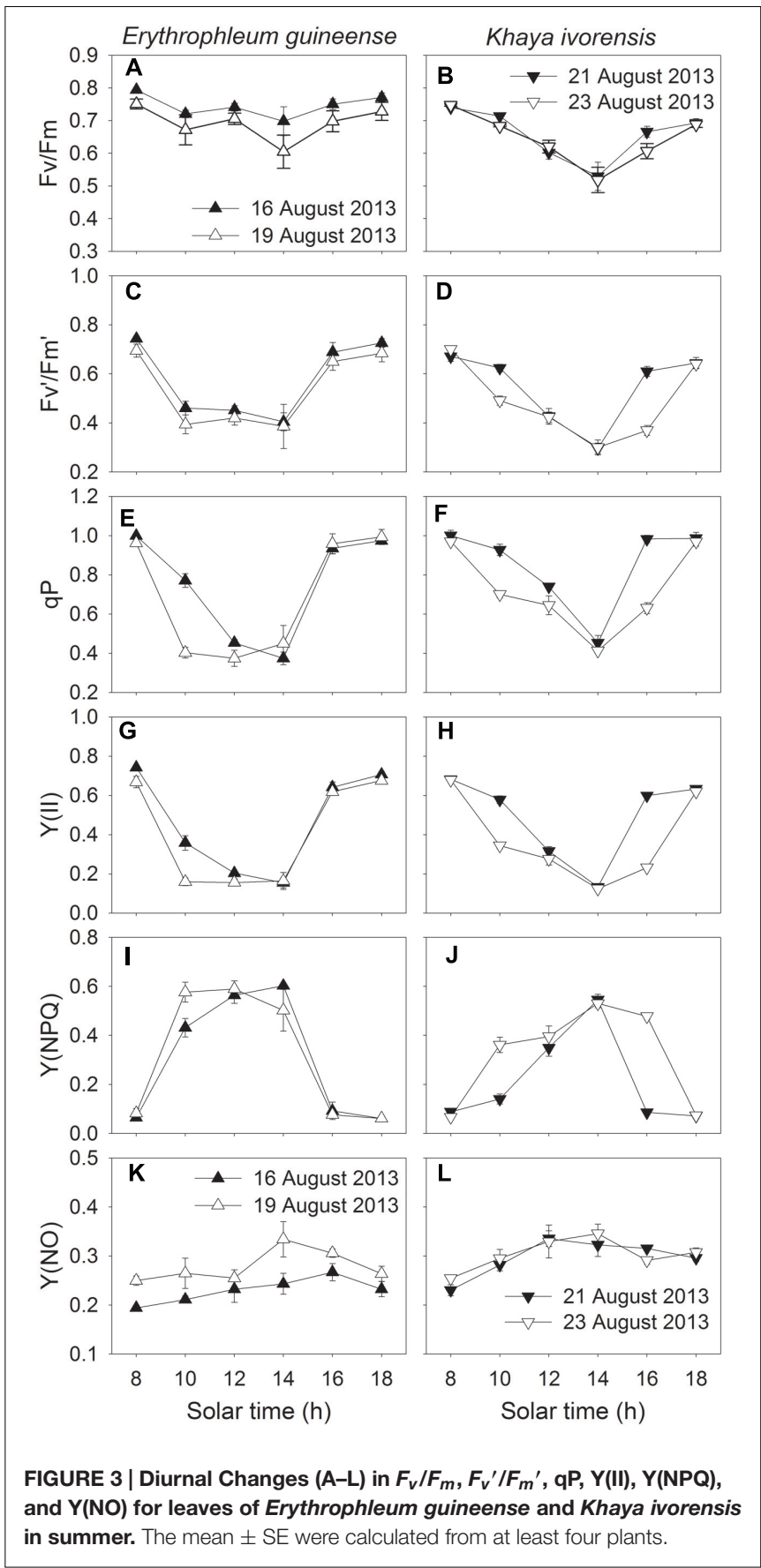

In the early morning, the values of ETRI, ETRII, and CEF were low in both species. The value of CEF/ETRII ratio at 8:00 was approximately 0.4 in E. guineense and 0.6 in $K$. ivorensis (Figures 5 and 6). ETRI and ETRII reached their maximum values at around 12:00 in both species (Figures 5 and 6). The value of CEF reaches its maximum value at approximately 14:00 (Figures 5 and 6). As a result, both species showed the maximum value of CEF/ETRII ratio approximately at 14:00 (Figures 5 and 6). In E. guineense, the maximum CEF/ETRII ratio on 16 August and 19 August were 1.18 and 1.25, respectively (Figure 5). In 

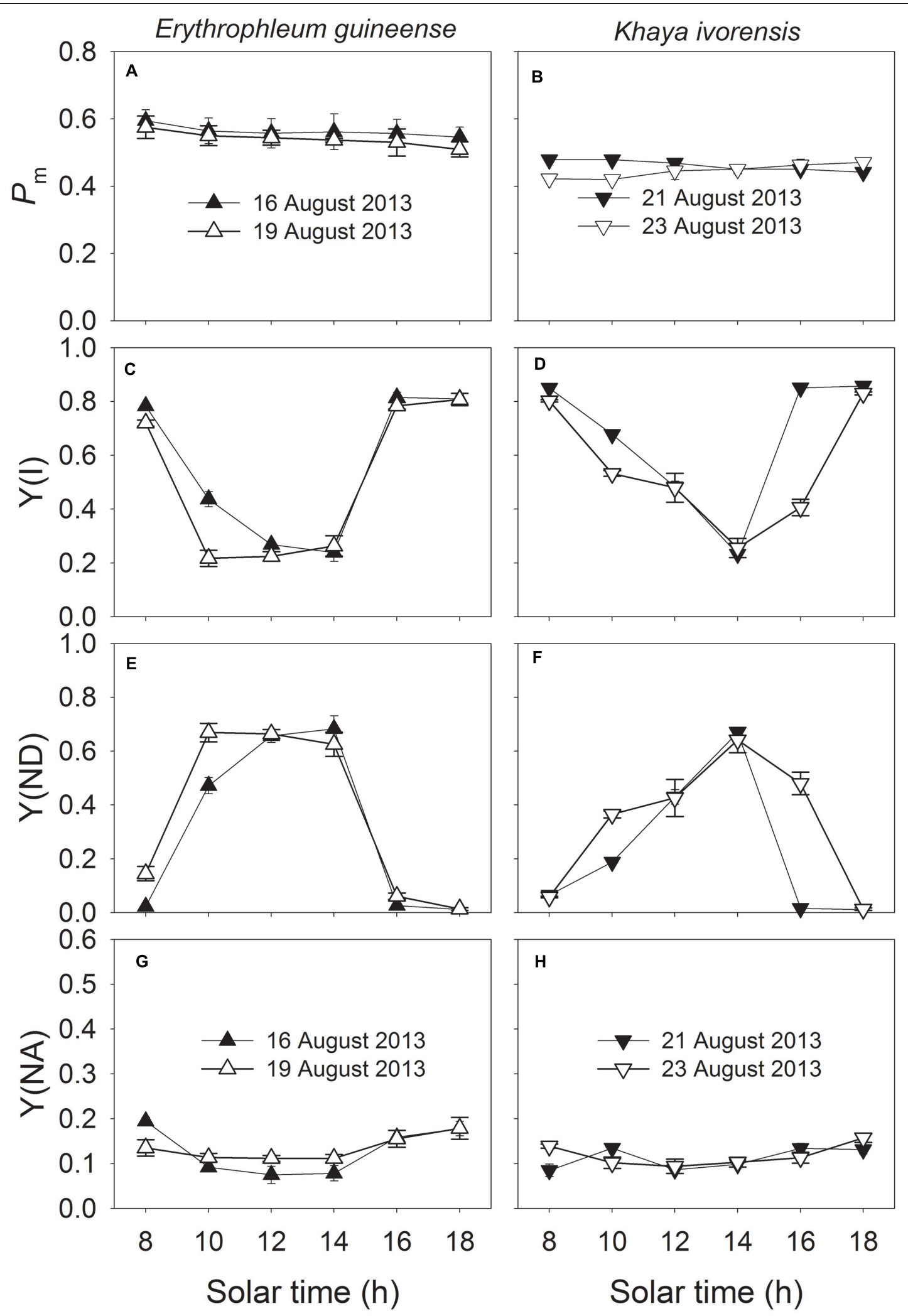

FIGURE 4 | Diurnal Changes (A-H) in $\boldsymbol{P}_{\boldsymbol{m}}, \mathrm{Y}(\mathrm{I}), \mathrm{Y}(\mathrm{ND})$, and $\mathrm{Y}(\mathrm{NA})$ for leaves of $\boldsymbol{E}$. guineense and $\boldsymbol{K}$. ivorensis in summer. The mean $\pm \mathrm{SE}$ were calculated from at least four plants. 


\section{Erythrophleum guineense}

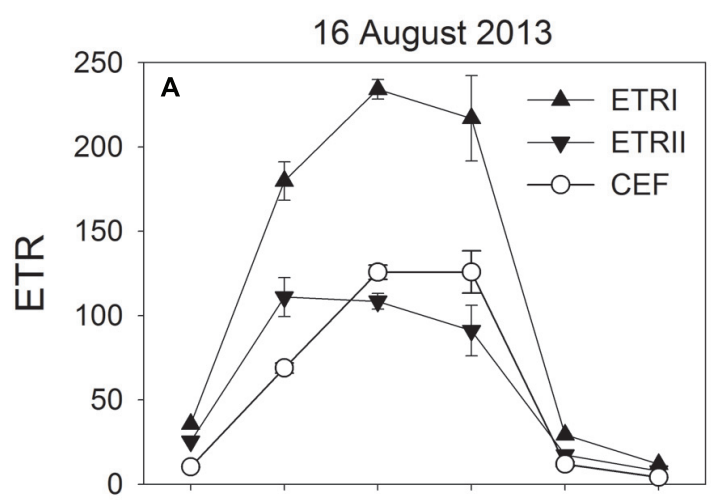

19 August 2013

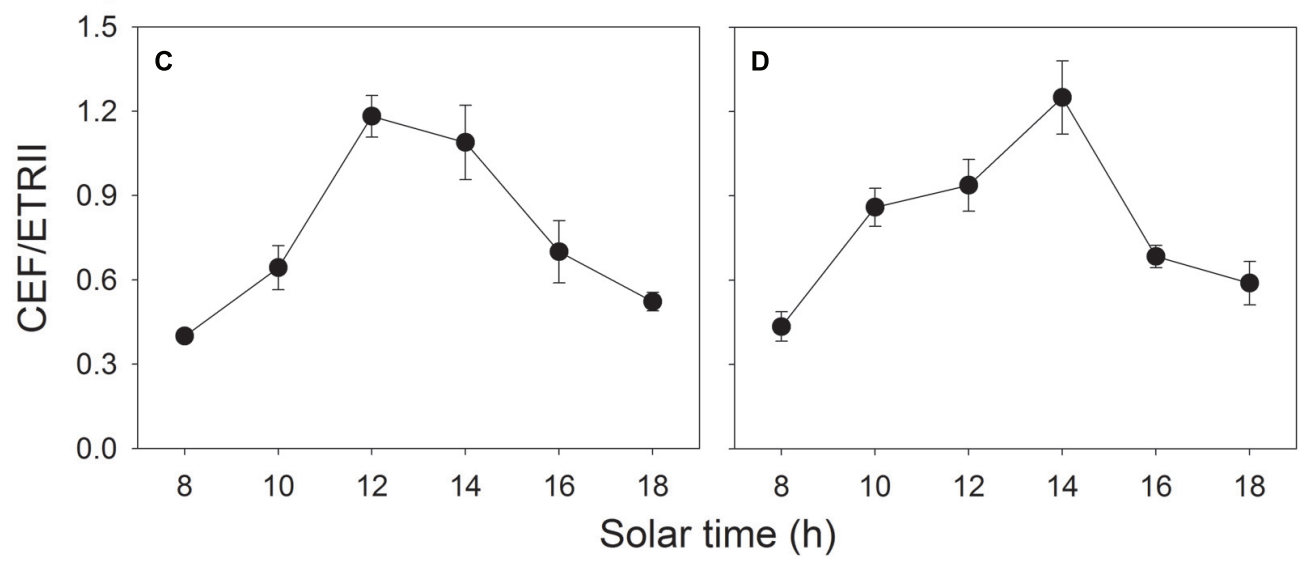

FIGURE 5 | Diurnal Changes (A-D) in ETRI, ETRII, CEF, and CEF/ETRII ratio for leaves of $E$. guineense in summer. The mean \pm SE were calculated from at least four plants.

K. ivorensis, the maximum CEF/ETRII ratio on 21 August and 23 August were 1.36 and 1.71 , respectively (Figure 6). In the afternoon, both species showed a significant stimulation in the $\mathrm{CEF}$ at low light, and the value of CEF/ETRII ratio changed from 0.5 to 0.8 in the two species (Figures 5 and 6). The value of CEF/ETRII ratio at 18:00 was significantly higher than that under a PPFD of $58 \mu \mathrm{mol}$ photons $\mathrm{m}^{-2} \mathrm{~s}^{-1}$ measured without PSII photoinhibition in both species (Figures 2 and 6). These results indicated that CEF was activated not only under high light at noon, but also under low light in the late afternoon.

\section{DISCUSSION}

\section{Estimation of the Rate of CEF}

Cyclic electron flow was discovered 50 years ago by Arnon (1959) and Tagawa et al. (1963). They have used in vitro system to study CEF, mainly by measuring the $\mathrm{O} / \mathrm{P}$ stoichiometry on isolated thylakoids and chloroplasts. However, it is complicated to distinguish between the main cyclic route and pseudocyclic (water-water cycle) till date. To understand the physiological function of CEF during a clear day, the activity of CEF should be evaluated. Three methods for the determination of CEF activity have been proposed and all depend on the exact determination of the P700 turnover rate (Miyake, 2010). The first was developed by Klüghammer and Schreiber (1994) group. The second was developed by Johnson (2003) and Nandha et al. (2007) group and the third was developed by Joliot and Joliot (2006) and Baker et al. (2007) group. The three methods reported an accurate result showing that $\mathrm{CEF}$ operates at a higher activity during the induction phase of photosynthesis (Joliot and Joliot, 2002; Maniko et al., 2002). Until now, Schreiber's method has been widely used to study or investigate CEF (Suorsa et al., 2012; Kono et al., 2014; Tikkanen et al., 2014, 2015; Kou et al., 2015). In our present study, we used Schreiber's method to determine CEF activity. Light response changes in $\mathrm{Y}(\mathrm{ND}), \mathrm{Y}(\mathrm{NA})$ and CEF in both studied species (Figure 2) were similar to those obtained in leaves of Arabidopsis wild-type (Kono et al., 2014; Kou et al., 2015; Tikkanen et al., 2015). This supports our findings and indicates the reliability and accuracy of this method.

\section{Stimulation of CEF at Noon}

We found that CEF was strongly stimulated at noon in the two species (Figures 5 and 6). At noon in a clear day, the increase in air temperature can increase both leaf temperature and the leaf-to-air vapor pressure deficit, which leads to partial stomatal closure and depression of photosynthesis (Zhang et al., 2009). 


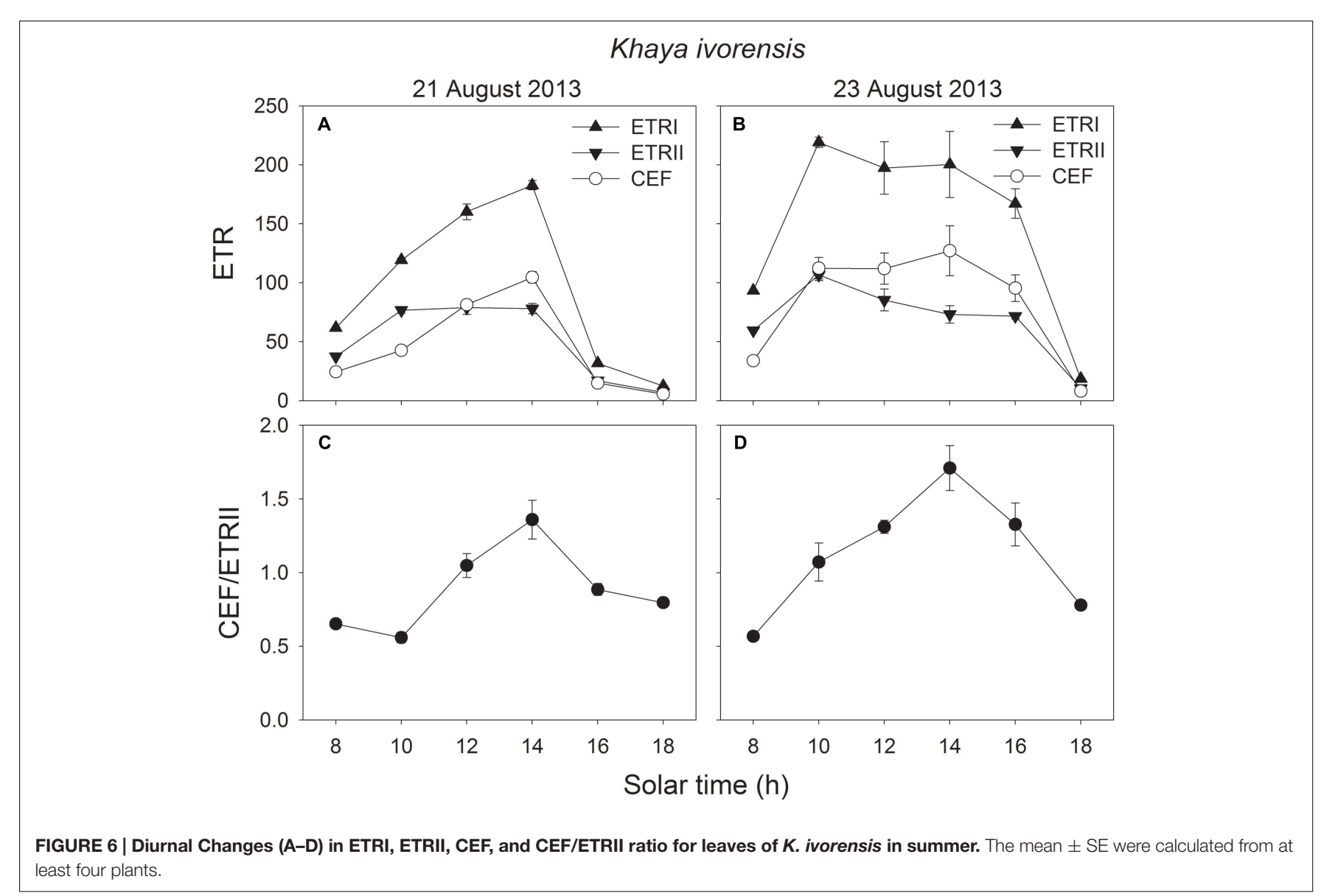

Several studies reported that CEF activity could be enhanced by heat stress in potato and spinach (Havaux, 1996; Bukhov et al., 1999; Kou et al., 2013). However, the decrease of CEF due to heat stress may occur in some heat-sensitive plant genotypes (Essemine et al., 2011; Brestic et al., 2016). Plants have the ability to quench excess light energy in PSII through NPQ, which is based on build-up of $\Delta \mathrm{pH}$ across thylakoid membranes (Munekage et al., 2002, 2004; Takahashi et al., 2009). CEF is necessary for the normal activation of NPQ in Arabidopsis illuminated under high light (Munekage et al., 2002, 2004; Nandha et al., 2007; Takahashi et al., 2009). In our present study, CEF was significantly stimulated at noon (Figures 5 and 6), which was accompanied with activation of $\mathrm{Y}(\mathrm{NPQ})$ (Figures 3I,J). These results suggested that CEF plays an important role in the activation of NPQ at noon, which may alleviate the production of ROS. It has been reported that ROS inhibit the repair of photoinhibited PSII (Nishiyama et al., 2001, 2004; Takahashi et al., 2009). Thus, it is very likely that the highly activation of CEF, at noon, favored the repair of photodamaged PSII.

Furthermore, some studies proposed that photodamage of PSII primarily occurred at the oxygen-evolving complex that is located on the luminal side of thylakoid membrane (Hakala et al., 2005; Ohnishi et al., 2005). Previous study suggested that a high concentration of $\mathrm{Ca}^{2+}$ in the lumen of thylakoids could stabilize the oxygen-evolving complex against photodamage (Krieger and Weis, 1993). Since acidification of the lumen could drive a $\mathrm{Ca}^{2+} / \mathrm{H}^{+}$antiport to sequester $\mathrm{Ca}^{2+}$ in the lumen, up to about $4 \mathrm{mM}$ in the lumen from an external concentration of $15 \mu \mathrm{M}$ (Ettinger et al., 1999), impairment of the generation of $\Delta \mathrm{pH}$ across the thylakoid membrane caused acceleration of the photodamage to PSII (Takahashi et al., 2009). Furthermore, the inhibition of CEF-dependent formation of $\Delta \mathrm{pH}$ could induce severe photodamage to PSII under high light (Takahashi et al., 2009; Tikkanen et al., 2014). Our recent study indicated that CEF played a significant role in the photoprotection for the oxygenevolving complex (Huang et al., 2016). The present results indicate a slightly or moderately photoinhibition of PSII during clear days. Therefore, the strong stimulation of CEF at noon likely protects PSII against photoinhibition through stabilizing the oxygen-evolving complex.

Our results indicated that the strong stimulation of CEF at noon prevents the PSI photoinhibition. Generally, PSI is insusceptible to high light stress in wild-type plants, which is partly explained by the high proportion of P700 accumulated in the oxidized state (Barth et al., 2001). Munekage et al. (2002, 2004) have reported that PGR5-dependent CEF is essential for photoprotection of PSI in Arabidopsis as evidenced by the small fraction of oxidized P700 in the pgr5 plants. Furthermore, a recent study indicated that PGR5-dependent CEF is necessary for PSI activity under fluctuating light conditions (Suorsa et al., 2012). 
PGR5-dependent CEF is responsible for photosynthetic control of electron transfer, which protects PSI from over-reduction and oxidative damage (Suorsa et al., 2012; Tikkanen et al., 2014). Since PSI photoinhibition is induced by the over accumulation of hydroxyl radicals which are generated between reduced PSI reaction centers and hydrogen peroxide (Sonoike, 1996a,b, 2006, 2011), the over-reduction of PSI acceptor side is a prerequisite for photoinhibition of PSI. In the present study, the stimulation of CEF increased the oxidation ratio of P700 and decreased the fraction of P700 that cannot be oxidized (Figure 4), indicating that the stimulation of CEF at noon prevents the over-reduction of PSI acceptor side. It was reported that high-light stress could decrease the fraction of photo-oxidized P700 in some plant grown in field (Endo et al., 2005). However, our results indicate that a large fraction of P700 was oxidized under high light at noon in the two species. This could occur by the diversion of electrons from reduced ferredoxin into CEF.

Furthermore, the over-accumulation of reducing power NADPH, resulting in generation of hydroxyl radicals in PSI reaction centers (Murata et al., 2007), is documented as a necessary mechanism for the photoinhibition of PSI (Wang et al., 2006; Shikanai, 2007). The inhibition of $\mathrm{CO}_{2}$ fixation at noon could induce the over-accumulation of NADPH so that could increase the risk of PSI photoinhibition. CEF could consume excess NADPH through the NADPH dehydrogenasedependent pathway (Shikanai, 2007). Chloroplastic NAD(P)H dehydrogenase in tobacco leaves functions in alleviation of oxidative damage caused by high temperature stress (Wang et al., 2006). The strong stimulation of CEF at noon suggested that it may protect PSI from photoinhibition through alleviating the over-accumulation of NADPH.

\section{Stimulation of CEF in the Afternoon}

In addition to photoprotection, another important role of CEF is to help extra ATP synthesis, which is necessary for optimal photosynthesis and PSII repair. Our results indicated that CEF was significantly stimulated at low light in the afternoon (Figures 5 and 6), which was accompanied with the fast repair of photodamaged PSII (Figure 3). The main feature of the repair process is the replacement of the D1 protein in the photodamaged PSII complexes by newly synthesized D1 and reassembly of active PSII (Guenther and Melis, 1990; Aro et al., 1993; Kettunen et al., 1997; Allakhverdiev et al., 2005). The fast repair of PSII photoinhibition is dependent on ATP synthesis (Allakhverdiev et al., 2005), which is in turn dependent on the formation of $\Delta \mathrm{pH}$ across thylakoid membranes. Our previous study suggested that CEF was stimulated under a low light to help the recovery of chilling-induced photoinhibition of PSII (Huang et al., 2010b). CEF-mutants of A. thaliana, ccr6 and pgr5, showed lower rate of $\mathrm{CO}_{2}$ assimilation under low light than wild type, suggesting that CEF activity could be important for ATP synthesis at low light (Yamori et al., 2011; Nishikawa et al., 2012). In the present studied two species, CEF was activated under low light in the late afternoon (Figures 5 and 6). Meanwhile, the values of Y(NPQ) and Y(ND) were maintained at low levels (Figures 3 and 4). These results indicated that, at low light in the afternoon, CEF-dependent generation of $\Delta \mathrm{pH}$ did not cause luminal acidification. As a result, in the afternoon, the CEF-dependent generation of $\Delta \mathrm{pH}$ probably contributed to ATP synthesis. These results suggest that the stimulation of CEF in the afternoon mainly helps the repair of PSII photoinhibition rather than contributes to photoprotection.

\section{The Physiological Significance of Stability of PSI Activity in the Daytime}

The present study showed that high light caused PSII photoinhibition in sun leaves at noon whereas the PSI activity remained very stable (Figures 3 and 4). A possible reason for the preference of maintaining stable PSI activity is that the repair of PSII activity is fast but the repair of PSI activity is relatively slow (Zhang and Scheller, 2004). Furthermore, the fast recovery of photodamaged PSII was dependent on a moderate PSI activity. Moderate PSI photoinhibition slowed the rate of PSII recovery (Kudoh and Sonoike, 2002), and severe PSI photoinhibition resulted in failure of recovery of both PSI and PSII from photoinhibition (Huang et al., 2010a). Therefore, the stability of PSI activity during the daytime contributed to the photoprotection and recovery of PSII activity. Additionally, the decrease of CEF-dependent formation of $\Delta \mathrm{pH}$ due to damage of PSI led to a substantial decrease of photosynthetic $\mathrm{CO}_{2}$ assimilation, especially at low light (Zivcak et al., 2015). Because the operation of CEF involves the assembly of super complex including PSI complex (Peng and Shikanai, 2011), we speculate that the main role of stability of PSI activity in the daytime is to guarantee the activation of CEF.

In summary, our results indicate that CEF was not only activated under high light at noon but as well at low light in the afternoon. The stimulation of CEF at noon has mainly two functions: one is alleviating PSII photoinhibition, and the other is preventing PSI photoinhibition. It is presumably that the stimulation of CEF during the afternoon helps mainly for the fast repair of PSII photoinhibition via ATP synthesis. The stability of PSI activity in the daytime guaranteed the stimulation of CEF and in turn favored photoprotection and repair of PSII photoinhibition.

\section{AUTHOR CONTRIBUTIONS}

WH and S-BZ conceived and designed research. WH and Y-JY conducted experiments. WH, Y-JY, and S-BZ analyzed data. WH, Y-JY, HH, K-FC, and S-BZ wrote the manuscript.

\section{FUNDING}

This study was supported by grants of National Natural Science Foundation of China (31300332 and 31170315).

\section{ACKNOWLEDGMENT}

The Xishuangbanna Station for Tropical Rain Forest Ecosystem Studies (XSTRE) provided climatic data. 


\section{REFERENCES}

Allakhverdiev, S. I., Nishiyama, Y., Takahashi, S., Miyairi, S., Suzuki, I., and Murata, N. (2005). Systematic analysis of the relation of electron transport and ATP synthesis to the photodamage and repair of photosystem II in synechocystis. Plant Physiol. 137, 263-273. doi: 10.1104/pp.104.054478

Allen, D. J., Ratner, K., Giller, Y. E., Gussakovsky, E. E., Shahak, Y., and Ort, D. R. (2000). An overnight chill induces a delayed inhibition of photosynthesis at midday in mango (Mangifera indica L.). J. Exp. Bot. 51, 1893-1902. doi: 10.1093/jexbot/51.352.1893

Arnon, D. I. (1959). Conversion of light into chemical energy in photosynthesis. Nature 184, 10-21.

Aro, E. M., Virgin, I., and Andersson, B. (1993). Photoinhibition of photosystem II. Inactivation, protein damage and turnover. Biochim. Biophys. Acta. 1143, 113-134. doi: 10.1016/0005-2728(93)90134-2

Asada, K. (1996). "Radical production and scavenging in the chloroplasts," in Photosynthesis and the Environment, ed. N. R. Barker (Dordrecht: Kluwer Academic Publishers), 123-320.

Asada, K. (1999). The water-water cycle in chloroplasts: scavenging of active oxygens and dissipation of excess photons. Ann. Rev. Plant Biol. 50, 601-639. doi: 10.1146/annurev.arplant.50.1.601

Asada, K., and Takahashi, M. (1987). "Production and scavenging of active oxygen in photosynthesis," in Photoinhibition, eds D. J. Kyle, C. B. Osmond, and C. J. Arntzen (Amsterdam: Elsevier), 227-287.

Baker, N. R., Harbinson, J., and Kramer, D. M. (2007). Determining the limitations and regulation of photosynthetic energy transduction in leaves. Plant Cell Environ. 30, 1107-1125. doi: 10.1111/j.1365-3040.2007.01680.x

Ballottari, M., Osto, L., Morosinotto, T., and Bassi, R. (2007). Contrasting behavior of higher plant photosystem I and II antenna systems during acclimation. J. Biol Chem. 282, 8947-8958. doi: 10.1074/jbc.M606417200

Barber, J., and Andersson, B. (1992). Too much of a good thing: light can be bad for photosynthesis. Trends. Biochem Sci. 17, 61-66. doi: 10.1016/09680004(92)90503-2

Barth, C., Krause, G. H., and Winter, K. (2001). Responses of photosystem I compared with photosystem II to high-light stress in tropical shade and sun leaves. Plant Cell Environ. 24, 163-176. doi: 10.1111/j.1365-3040.2001. 00673.x

Brestic, M., Zivcak, M., Kunderlikova, K., and Allakhverdiev, S. I. (2016). High temperature specifically affects the photoprotective responses of chlorophyll b-deficient wheat mutant lines. Photosynth. Res. doi: 10.1007/s11120-016-02497 [Epub ahead of print].

Brestic, M., Zivcak, M., Kunderlikova, K., Sytar, O., Shao, H., Kalaji, H. M., et al. (2015). Low PSI content limits the photoprotection of PSI and PSII in early growth stages of chlorophyll b-deficient wheat mutant lines. Photosynth. Res. 125, 151-166. doi: 10.1007/s11120-015-0093-1

Bukhov, N. G., Wiese, C., Neimanis, S., and Heber, U. (1999). Heat sensitivity of chloroplasts and leaves: leakage of protons from thylakoids and reversible activation of cyclic electron transport. Photosynth. Res. 59, 81-93. doi: 10.1023/A:1006149317411

Demmig-Adams, B. (1990). Carotenoids and photoprotection in plants: a role for the xanthophyll zeaxanthin. Biochim. Biophys. Acta. 1020, 1-24. doi: 10.1016/0005-2728(90)90088-L

Endo, T., Kawase, D., and Sato, F. (2005). Stromal over-reduction by highlight stress as measured by decreases in P700 oxidation by far-red light and its physiological relevance. Plant Cell Physiol. 46, 775-781. doi: $10.1093 / \mathrm{pcp} / \mathrm{pci0} 84$

Essemine, J., Govindachary, S., Ammar, S., Bouzid, S., and Carpentier, R. (2011). Abolition of photosystem I cyclic electron flow in Arabidopsis thaliana following thermal-stress. Plant Physiol. Biochem. 49, 235-243. doi: 10.1016/j.plaphy.2010.11.002

Essemine, J., Qu, M., Mi, H., and Zhu, X. G. (2016). Response of chloroplast $\mathrm{NAD}(\mathrm{P}) \mathrm{H}$ dehydrogenase-mediated cyclic electron flow to a shortage or lack in ferredoxin-quinone oxidoreductase-dependent pathway in rice following short-term heat stress. Front. Plant Sci. 7:383. doi: 10.3389/fpls.2016. 00383

Ettinger, W. F., Clear, A. M., Fanning, K. J., and Peck, M. L. (1999). Identification of $\mathrm{a} \mathrm{Ca}^{2+} / \mathrm{H}^{+}$antiport in the plant chloroplast thylakoid membrane. Plant Physiol. 119, 1379-1385. doi: 10.1104/pp.119.4.1379
Genty, B., Briantais, J. M., and Baker, N. R. (1989). The relationship between the quantum yield of photosynthetic electron transport and quenching of chlorophyll fluorescence. Biochim. Biophy. Acta 990, 87-92. doi: 10.1016/S03044165(89)80016-9

Guenther, J. E., and Melis, A. (1990). The physiological significance of photosystem II heterogeneity in chloroplasts. Photosynth. Res. 23, 105-109. doi: 10.1007/BF00030070

Hakala, M., Tuominen, I., Keranen, M., Tyystjarvi, T., and Tyystjarvi, E. (2005). Evidence for the role of the oxygen-evolving manganese complex in photoinhibition of photosystem II. Biochim. Biophys. Acta 1706, 68-80. doi: 10.1016/j.bbabio.2004.09.001

Havaux, M. (1996). Short-term responses of photosystem I to heat stress. Photosynth. Res. 47, 85-97. doi: 10.1007/BF00017756

Havaux, M., and Davaud, A. (1994). Photoinhibition of photosynthesis in chilled potato leaves is not correlated with a loss of photosystem-II activity preferential inactivation of photosystem I. Photosynth. Res. 40, 75-92. doi: 10.1007/BF00019047

He, J., and Chow, W. S. (2003). The rate coefficient of repair of photosystem II after photoinactivation. Physiol. Plant. 118, 297-304. doi: 10.1034/j.13993054.2003.00107.x

Hendrickson, L., Ball, M. C., Wood, J. T., Chow, W. S., and Furbank, R. T. (2004a). Low temperature effects on photosynthesis and growth of grapevine. Plant Cell Environ. 27, 795-809. doi: 10.1111/j.1365-3040.2004.01184.x

Hendrickson, L., Furbank, R. T., and Chow, W. S. (2004b). A simple alternative approach to assessing the fate of absorbed light energy using chlorophyll fluorescence. Photosynth. Res. 82, 73-81. doi: 10.1023/B:PRES.0000040446.87305.f4

Huang, W., Fu, P. L., Jiang, Y. J., Zhang, J. L., Zhang, S. B., Hu, H., et al. (2013). Differences in the responses of photosystem I and photosystem II of three tree species Cleistanthus sumatranus, Celtis philippensis and Pistacia weinmannifolia submitted to a prolonged drought in a tropical limestone forest. Tree Physiol. 33, 211-220. doi: 10.1093/treephys/tps132

Huang, W., Yang, S. J., Zhang, S. B., Zhang, J. L., and Cao, K. F. (2012). Cyclic electron flow plays an important role in photoprotection for the resurrection plant Paraboea rufescens under drought stress. Planta 235, 819-828. doi: 10.1007/s00425-011-1544-3

Huang, W., Yang, Y. J., Hu, H., and Zhang, S. B. (2015). Different roles of cyclic electron flow around photosystem I under sub-saturating and saturating light intensities in tobacco leaves. Front. Plant Sci. 6:923. doi: 10.3389/fpls.2015.00923

Huang, W., Yang, Y. J., Hu, H., Zhang, S. B., and Cao, K. F. (2016). Evidence for the role of cyclic electron flow in photoprotection for oxygen-evolving complex. J. Plant Physiol. 194, 54-60. doi: 10.1016/j.jplph.2016.02.016

Huang, W., Zhang, S. B., and Cao, K. F. (2010a). The different effects of chilling stress under moderate illumination on photosystem II compared with photosystem I and subsequent recovery in tropical tree species. Photosynth. Res. 103, 175-182. doi: 10.1007/s11120-010-9539-7

Huang, W., Zhang, S. B., and Cao, K. F. (2010b). Stimulation of cyclic electron flow during recovery after chilling-induced photoinhibition of PSII. Plant Cell Physiol. 51, 1922-1928. doi: 10.1093/pcp/pcq144

Huang, W., Zhang, S. B., and Cao, K. F. (2011). Cyclic electron flow plays an important role in photoprotection of tropical trees illuminated at temporal chilling temperature. Plant Cell Physiol. 52, 297-305.

Johnson, G. N. (2003). Thiol regulation of the thylakoid electron transport chain-a missing link in the regulation of photosynthesis? Biochemistry 42, 3040-3044. doi: $10.1021 /$ bi027011k

Joliot, P., and Joliot, A. (2002). Cyclic electron flow in plant leaf. Proc. Natl. Acad Sci. U.S.A. 99, 10209-10214. doi: 10.1073/pnas.102306999

Joliot, P., and Joliot, A. (2006). Cyclic electron flow in C3 plants. Biochim. Biophys. Acta 1757, 362-368. doi: 10.1016/j.bbabio.2006.02.018

Kettunen, R., Pursiheimo, S., Rintamaki, E., van Wijk, K. J., Joliot, P., Joliot, A., et al. (1997). Transcriptional and translational adjustments of psbA gene expression in mature chloroplasts during photoinhibition and subsequent repair of photosystem II. Eur. J. Biochem. 247, 441-448. doi: 10.1111/j.14321033.1997.00441.x

Klüghammer, C., and Schreiber, U. (1994). An improved method, using saturating light pulses, for the determination of photosystem I quantum yield via P700+absorbance changes at $830 \mathrm{~nm}$. Planta 192, 261-268. doi: 10.1007/BF01089043 
Klüghammer, C., and Schreiber, U. (2008). Saturation pulse method for assessment of energy conversion in PSI. PAM Appl. Notes 1, 11-14.

Kono, M., Noguchi, K., and Terashima, I. (2014). Roles of the cyclic electron flow around PSI (CEF-PSI) and O2-dependent alternative pathways in regulation of the photosynthetic electron flow in short-term fluctuating light in Arabidopsis thaliana. Plant Cell Physiol. 55, 990-1004. doi: 10.1093/pcp/pcu033

Kou, J. C., Takahashi, S., Fan, D. Y., Badger, M. R., and Chow, W. S. (2015). Partially dissecting the steady-state electron fluxes in Photosystem I in wildtype and pgr5 and ndh mutants of Arabidopsis. Front. Plant Sci. 6:758. doi: $10.3389 /$ fpls.2015.00758

Kou, J. C., Takahashi, S., Oguchi, R., Fan, D. Y., Badger, M. R., and Chow, W. S. (2013). Estimation of the steady-state cyclic electron flux around PSI in spinach leaf discs in white light, $\mathrm{CO} 2$-enriched air and other varied conditions. Funct. Plant Biol. 40, 1018-1028.

Kramer, D. M., Johnson, G., Kiirats, O., and Edwards, G. E. (2004). New fluorescence parameters for the determination of QA redox state and excitation energy fluxes. Photosynth. Res. 79, 209-218. doi: 10.1023/B:PRES.0000015391.99477.0d

Krieger, A., and Weis, E. (1993). The role of calcium in the pH-dependent control of Photosystem II. Photosynth. Res. 37, 117-130. doi: 10.1007/BF02187470

Kudoh, H., and Sonoike, K. (2002). Irreversible damage to photosystem I by chilling in the light: cause of the degradation of chlorophyll after returning to normal growth temperature. Planta 215, 541-548. doi: 10.1007/s00425-002$0790-9$

Maniko, A., Miyake, C., and Yokota, A. (2002). Physiological functions of the water-water cycle (Mehler reaction) and the cyclic electron flow around PSI in rice leaves. Plant Cell Physiol. 43, 1017-1026. doi: 10.1093/pcp/pcf124

Miyake, C. (2010). Alternative electron flows (water-water cycle and cyclic electron flow around PSI) in photosynthesis: molecular mechanisms and physiological functions. Plant Cell Physiol. 51, 1951-1963. doi: 10.1093/pcp/ pcq173

Miyake, C., Horiguchi, S., Makino, A., Shinzaki, Y., Yamamoto, H., and Tomizawa, K. (2005). Effects of light intensity on cyclic electron flow around PSI and its relationship to non-photochemical quenching of chl fluorescence in tobacco leaves. Plant Cell Physiol. 46, 1819-1830. doi: 10.1093/pcp/pci197

Munekage, Y., Hashimoto, M., Miyake, C., Tomizawa, K. I., Endo, T., Tasaka, M., et al. (2004). Cyclic electron flow around photosystem I is essential for photosynthesis. Nature 429, 579-582. doi: 10.1038/nature02598

Munekage, Y., Hojo, M., Meurer, J., Endo, T., Tasaka, M., and Shikanai, T. (2002). PGR5 is involved in cyclic electron flow around photosystem I and is essential for photoprotection in Arabidopsis. Cell 110, 361-371. doi: 10.1016/S00928674(02)00867-X

Murata, N., Takahashi, S., Nishiyama, Y., and Allakhverdiev, S. I. (2007). Photoinhibition of photosystem II under environmental stress. Biochim. Biophys. Acta. 1767, 414-421. doi: 10.1016/j.bbabio.2006.11.019

Nandha, B., Finazzi, G., Joliot, P., Hald, S., and Johnson, G. N. (2007). The role of PGR5 in the redox poising of photosynthetic electron transport. Biochim. Biophys. Acta 1767, 1252-1259. doi: 10.1016/j.bbabio.2007.07.007

Nishikawa, Y., Yamamoto, H., Okegawa, Y., Wada, S., Sato, N., Taira, Y., et al. (2012). PGR5-dependent cyclic electron transport around PSI contributes to the redox homeostasis in chloroplasts rather than $\mathrm{CO}_{2}$ fixation and biomass production in rice. Plant Cell Physiol. 53, 2117-2126. doi: 10.1093/pcp/pcs153

Nishiyama, Y., Allakhverdiev, S. I., Yamamoto, H., Hayashi, H., and Murata, N. (2004). Singlet oxygen inhibits the repair of photosystem II by suppressing the translation elongation of the D1 protein in Synechocystis sp. PCC 6803. Biochemistry 43, 11321-11330.

Nishiyama, Y., Yamamoto, H., Allakhverdiev, S. I., Inaba, M., Yokota, A., and Murata, N. (2001). Oxidative stress inhibits the repair of photodamage to the photosynthetic machinery. EMBO J. 20, 5587-5594. doi: 10.1093/emboj/20.20.5587

Niyogi, K. K., Grossman, A. R., and Bjorkman, O. (1998). Arabidopsis mutants define a central role for the xanthophyll cycle in regulation of photosynthetic energy conversion. Plant Cell 10, 1121-1134. doi: 10.2307/3870716

Niyogi, K. K., Shih, C., Chow, W. S., Pogson, B. J., DellaPenna, D., and Bjorkman, O. (2001). Photoprotection in a zeaxanthin and lutein deficient double mutant of Arabidopsis. Photosynth. Res. 67, 139-145. doi: 10.1023/A:1010661102365
Oguchi, R., Terashima, I., and Chow, W. S. (2009). The involvement of dual mechanisms of photoinactivation of photosystem II in Capsicum annuum L. plants. Plant Cell Physiol. 50, 1815-1825. doi: 10.1093/pcp/pcp123

Ohnishi, N., Allakhverdiev, S. I., Takahashi, S., Higashi, S., Watanabe, M., Nishiyama, Y., et al. (2005). Two-step mechanism of photodamage to photosystem II: step one occurs at the oxygen-evolving complex and step two occurs at the photochemical reaction center. Biochemistry 44, 8494-8499. doi: 10.1021/bi047518q

Oxborough, K., and Baker, N. R. (1997). Resolving chlorophyll a fluorescence images of photosynthetic efficiency into photochemical and nonphotochemical components - calculation of $\mathrm{qP}$ and $\mathrm{Fv}^{\prime} / \mathrm{Fm}^{\prime}$ without measuring Fo'. Photosynth. Res. 54, 135-142. doi: 10.1023/A:1005936823310

Peng, L., and Shikanai, T. (2011). Supercomplex formation with photosystem I is required for the stabilization of the chloroplast NADH dehydrogenaselike complex in Arabidopsis. Plant Physiol. 155, 1629-1639. doi: 10.1104/pp.110.171264

Powles, S. B. (1984). Photoinhibition of photosynthesis induced by visible light. Annu. Rev. Plant Physiol. 35, 15-44. doi: 10.1146/annurev.pp.35.060184. 000311

Prasil, O., Adir, N., and Ohad, I. (1992). "Dynamics of photosystem II: mechanism of photoinhibition and recovery processes," in Topics in Photosynthesis, ed. J. Barber (Amsterdam: Elsevier), 295-348.

Shikanai, T. (2007). Cyclic electron transport around photosystem I: genetic approaches. Annu. Rev. Plant Biol. 58, 199-217. doi: 10.1146/annurev.arplant.58.091406.110525

Sonoike, K. (1995). Selective photoinhibition of photosystem I in isolated thylakoid membranes from cucumber and spinach. Plant Cell Physiol. 36, 825-830.

Sonoike, K. (1996a). Degradation of psa B gene product, the reaction center subunit of photosystem I, is caused during photoinhibition of photosystem I: possible involvement of active oxygen species. Plant Sci. 115, 157-164. doi: 10.1016/0168-9452(96)04341-5

Sonoike, K. (1996b). Photoinhibition of photosystem I: its physiological significance in the chilling sensitivity of plants. Plant Cell Physiol. 37, 239-247. doi: 10.1093/oxfordjournals.pcp.a028938

Sonoike, K. (2006). "Photoinhibition and protection of photosystem I," in Photosystem I: The Light-Driven Plastocyanin: Ferredoxin Oxidoreductase, Series Advances in Photosynthesis and Respiration, ed. J. H. Golbeck (Dordrecht: Springer), 657-668.

Sonoike, K. (2011). Photoinhibition of photosystem I. Physiol. Plant. 142, 56-64. doi: 10.1111/j.1399-3054.2010.01437.x

Sundby, C., Chow, W. S., and Anderson, J. M. (1993). Effects on photosystem II function, photoinhibition, and plant performance of the spontaneous mutation of serine-264 in the photosystem II reaction center D1 protein in triazineresistant Brassica napus L. Plant Physiol. 103, 105-113.

Suorsa, M., Jarvi, S., Grieco, M., Nurmi, M., Pietrzykowska, M., Rantala, M., et al. (2012). PROTON GRADIENT REGULATION5 is essential for proper acclimation of Arabidopsis photosystem I to naturally and artificially fluctuating light conditions. Plant Cell 24, 2934-2948. doi: 10.1105/tpc.112.097162

Tagawa, A., Tsujimoto, H. Y., and Arnon, D. I. (1963). Role of chloroplast ferredoxin in the energy conversion process of photosynthesis. Proc. Natl. Acad. Sci. U.S.A. 49, 567-572. doi: 10.1073/pnas.49.4.567

Takahashi, S., Milward, S. E., Fan, D. Y., Chow, W. S., and Badger, M. R. (2009). How does cyclic electron flow alleviate photoinhibition in Arabidopsis? Plant Physiol. 149, 1560-1567. doi: 10.1104/pp.108.134122

Takahashi, S., and Murata, N. (2005). Interruption of the Calvin cycle inhibits the repair of Photosystem II from photodamage. Biochim. Biophys. Acta. 1708, 352-361. doi: 10.1016/j.bbabio.2005.04.003

Takahashi, S., and Murata, N. (2006). Glycerate-3-phosphate, produced by $\mathrm{CO} 2$ fixation in the Calvin cycle, is critical for the synthesis of the D1 protein of photosystem II. Biochim. Biophys. Acta. 1757, 198-205. doi: 10.1016/j.bbabio.2006.02.002

Takahashi, S., and Murata, N. (2008). How do environmental stresses accelerate photoinhibition? Trend. Plant Sci. 13, 178-182. doi: 10.1016/j.tplants.2008.01.005

Tikkanen, M., Mekala, N. R., and Aro, E. M. (2014). Photosystem II photoinhibition-repair cycle protects Photosystem I from irreversible damage. Biochim. Biophys. Acta 1837, 210-215. doi: 10.1016/j.bbabio.2013.10.001 
Tikkanen, M., Rantala, S., and Aro, E. M. (2015). Electron flow from PSII to PSI under high light is controlled by PGR5 but not by PSBS. Front. Plant Sci. 6:521. doi: $10.3389 /$ fpls.2015.00521

Wang, P., Duan, W., Takabayashi, A., Endo, T., Shikanai, T., Ye, J. Y., et al. (2006). Chloroplastic NAD(P)H dehydrogenase in tobacco leaves functions in alleviation of oxidative damage caused by temperature stress. Plant Physiol. 141, 465-474. doi: 10.1104/pp.105.070490

Yamori, W., Sakata, N., Suzuki, Y., Shikanai, T., and Makino, A. (2011). Cyclic electron flow around photosystem I via chloroplast $\mathrm{NAD}(\mathrm{P}) \mathrm{H}$ dehydrogenase (NDH) complex performs a significant physiological role during photosynthesis and plant growth at low temperature in rice. Plant J. 68, 966-976. doi: 10.1111/j.1365-313X.2011.04747.x

Zhang, J. L., Meng, L. Z., and Cao, K. F. (2009). Sustained diurnal photosynthetic depression in uppermost-canopy leaves of four dipterocarp species in the rainy and dry seasons: does photorespiration play a role in photoprotection? Tree Physiol. 29, 217-228. doi: 10.1093/treephys/tpn018

Zhang, S. P., and Scheller, H. V. (2004). Photoinhibition of photosystem I at chilling temperature and subsequent recovery in Arabidopsis. Plant Cell Physiol. 45, 1595-1602. doi: 10.1093/pcp/pch180

Zivcak, M., Brestic, M., Balatova, Z., Drevenakova, P., Olsovska, K., Kalaji, H. M., et al. (2013). Photosynthetic electron transport and specific photoprotective responses in wheat leaves under drought stress. Photosynth. Res. 117, 529-546. doi: $10.1007 /$ s11120-013-9885-3

Zivcak, M., Brestic, M., Kalaji, H. M., and Govindjee. (2014). Photosynthetic responses of sun- and shade-grown barley leaves to high light: is the lower PSII connectivity in shade leaves associated with protection against excess of light? Photosynth. Res. 119, 339-354. doi: 10.1007/s11120-014-9969-8

Zivcak, M., Brestic, M., Kunderlikova, K., Sytar, O., and Allakhverdiev, S. I. (2015). Repetitive light pulse-induced photoinhibition of photosystem I severely affects $\mathrm{CO}_{2}$ assimilation and photoprotection in wheat leaves. Photosynth. Res. 126, 449-463. doi: 10.1007/s11120-015-0121-1

Conflict of Interest Statement: The authors declare that the research was conducted in the absence of any commercial or financial relationships that could be construed as a potential conflict of interest.

Copyright (c) 2016 Huang, Yang, Hu, Cao and Zhang. This is an open-access article distributed under the terms of the Creative Commons Attribution License (CC BY). The use, distribution or reproduction in other forums is permitted, provided the original author(s) or licensor are credited and that the original publication in this journal is cited, in accordance with accepted academic practice. No use, distribution or reproduction is permitted which does not comply with these terms. 